\title{
Parathyroid carcinoma associated with chronic renal failure and previous radiotherapy to the neck
}

\author{
JP IRELAND, ${ }^{*}$ SJ FLEMING,$\dagger$ DA LEVISON, ${ }^{*}$ WR CATTELL, $\dagger$ LRI BAKER $\dagger$ \\ From the Departments of ${ }^{*}$ Histopathology and $\dagger$ Nephrology, St Bartholomew's Hospital and Medical \\ College, London
}

SUMMARY Carcinoma of the larynx was treated by irradiation followed by laryngectomy in a man who had been receiving regular haemodialysis for two years. At least one, and probably two, parathyroid glands were removed at this time, and the remaining two were removed three years later for tertiary hyperparathyroidism. A portion of one gland was implanted into the forearm. The forearm implant was resected the following year for recurrent hypercalcaemia. Six years later, again with recurrent hypercalcaemia, he died of bronchopneumonia. Metastatic parathyroid carcinoma was found in the apex of the left lung. The source of this parathyroid tissue and the possible role of irradiation in the pathogenesis of parathyroid cancer in this patient were investigated.

Parathyroid carcinoma may present diagnostic difficulty to both clinicians and histopathologists. We describe a man with tertiary hyperparathyroidism and systemic sarcoidosis who had previously received radiotherapy to the neck for laryngeal carcinoma and was receiving regular haemodialysis, in whom the diagnosis of parathyroid carcinoma was made only at necropsy. This case illustrates the diagnostic difficulties sometimes presented by the condition and raises the question of the possible role of radiation in inducing malignant change in parathyroid tissue already stimulated as a result of longstanding renal failure.

\section{CASE REPORT}

A 34 year old man began regular haemodialysis for chronic renal failure resulting from congenital hypoplasia of a solitary right kidney in 1972. Two years later a squamous carcinoma of the larynx was treated with radiotherapy (total dose $3250 \mathrm{cGy}$ divided into six doses over 18 days: source, Co II, field $7 \times 7 \mathrm{~cm})$. His chest was screened during radiation. The carcinoma was not cured, and total laryngectomy, which included removal of the left lobe of the thyroid and at least one, but probably both, left parathyroids, was carried out four months later. Serum calcium concentration was $2.76 \mathrm{mmol} / \mathrm{l}$ $(11 \mathrm{mg} / 100 \mathrm{ml}$ ) (corrected to a serum albumin concentration of $41 \mathrm{~g} / \mathrm{l}$, as described by Tomlinson and

Accepted for publication 17 June 1985
O' Riordan'; normal range $2 \cdot 20-2 \cdot 70 \mathrm{mmol} / 1(8 \cdot 8-\vec{\ominus}$ $10.8 \mathrm{mg} / 100 \mathrm{ml})$ ) and alkaline phosphatase 580 of IU/l (normal range 25-100). Fig. 1 shows the seriał. D calcium measurements recorded. Hilar lym phadenopathy and miliary mottling were noted on a chest radiograph.

By 1977 he had developed symptomatic hypercalcaemia (serum calcium concentration $3.07 \mathrm{mmol} / \mathrm{l}$ $(12.3 \mathrm{mg} / 100 \mathrm{ml})$ and alkaline phosphatase $169 \mathrm{IU} /$ 1). Serum parathyroid hormone concentration $(N$ terminal assay ${ }^{2}$ ) was raised at $1.43 \mu \mathrm{g} / \mathrm{l}$ (normal $<0.73 \mu \mathrm{g} / \mathrm{l}$ ). Digital subperiosteal erosions were visible on radiography. Hydrocortisone $40 \mathrm{mg}$ was given thrice daily for 30 days: no change in serum calcium concentration occurred, suggesting that hyperparathyroidism was the cause of the hypercalcaemia. At an exploration of the neck in July 1977 both right parathyroid glands were enlarged (see below) and were excised intact. About one third of the superior parathyroid $(0.3 \times 1.0 \mathrm{~cm})$ was implanted into the right forearm. Serum calcium concentration fell immediately to $1.50 \mathrm{mmol} / \mathrm{l}(6$ $\mathrm{mg} / 100 \mathrm{ml}$ ) and he was given a course of oral calcium supplement and $1 \alpha$-cholecalciferol. By November 1977 serum calcium concentration was $2.32 \mathrm{mmol} / \mathrm{l}(9.3 \mathrm{mg} / 100 \mathrm{ml})$ and alkaline phosphatase $102 \mathrm{IU} / \mathrm{l}$ while parathyroid concentrations in venous blood samples taken from the right and left arm were 0.70 and $0.95 \mathrm{ng} / \mathrm{ml}$, respectively (mixed assay, $N$ and $C$ terminals, ${ }^{3}$ normal range $0 \cdot 15-1 \cdot 0$ $\mathrm{ng} / \mathrm{ml}$ ). 


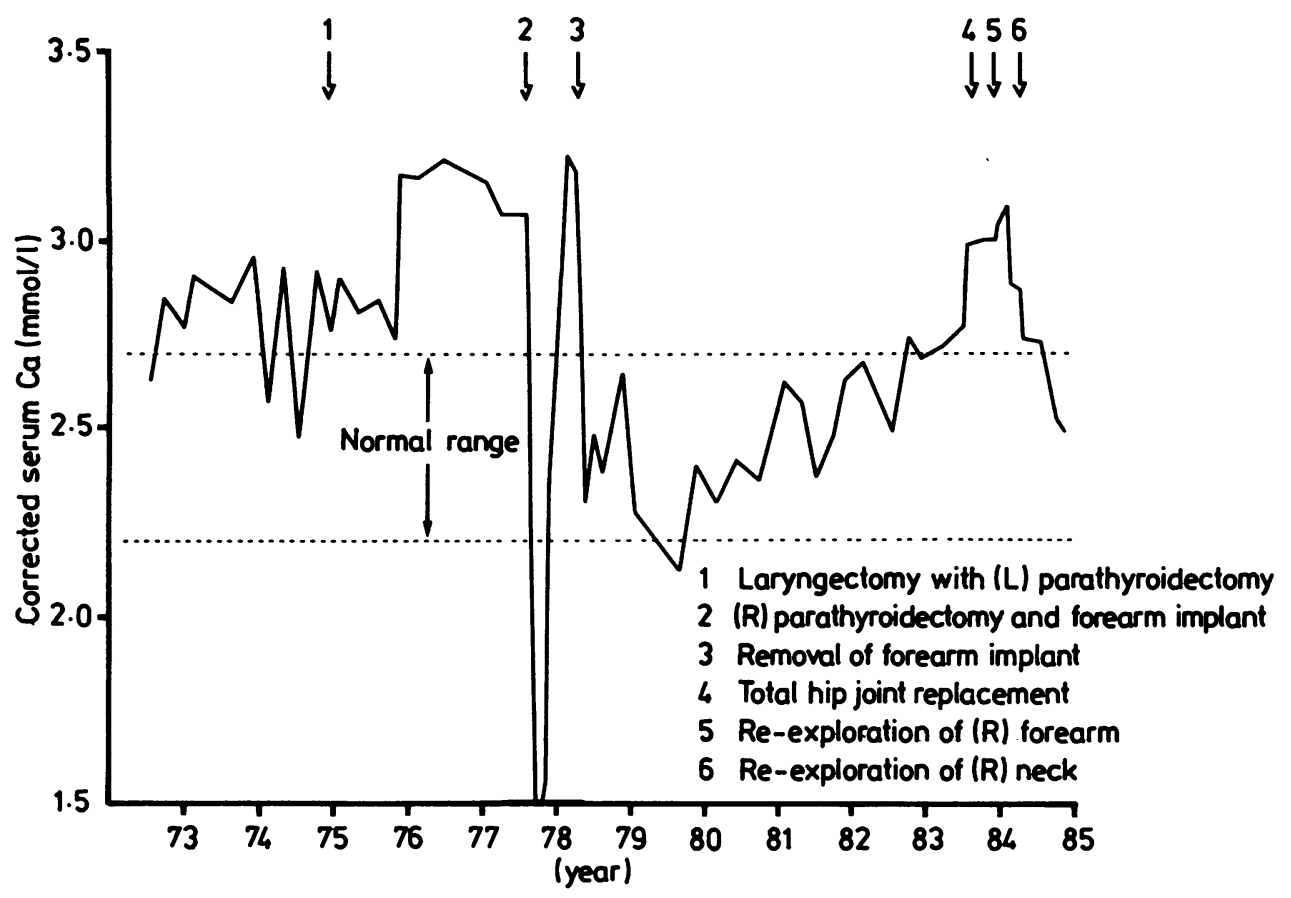

Fig. 1 Serial calcium measurements and key clinical events 1974-84.

By January 1978 despite withdrawal of the calcium supplement and $1 \alpha$-cholecalciferol he was again hypercalcaemic (serum calcium $2.93 \mathrm{mmol} / \mathrm{l}$ $(11.7 \mathrm{mg} / 100 \mathrm{ml}))$ with a raised parathyroid hormone concentration $\left(10 \mathrm{ng} / \mathrm{ml}\right.$, mixed assay $\left.{ }^{3}\right)$. The parathyroid implant was larger, and in March 1978 the implant was excised with immediate restoration of serum calcium concentration to normal.

In April 1979 he developed intermittent fever and pain in the joints and was found to have hepatosplenomegaly and haemolytic anaemia. Bone marrow biopsy showed several non-caseating granulomas. Ziehl-Neelsen stains gave negative results. There had been further progression of the

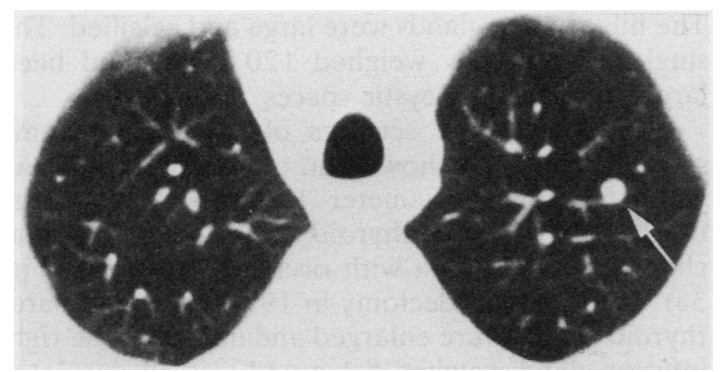

Fig. 2 Computed tomogram of the lung with parathyroid metastasis (arrowed). changes noted on the chest radiograph in 1976 . Systemic sarcoidosis was diagnosed, and he was given a course of oral prednisolone, resulting in good symptomatic relief. Hepatosplenomegaly regressed, and he became less anaemic.

In July 1983 he abruptly developed pain in the right hip on getting out of bed and was found to have a fracture of the femoral neck. Total hip replacement was carried out. At that time he was again hypercalcaemic (serum calcium $2.97 \mathrm{mmol} / 1$ (11.9 $\mathrm{mg} / 100 \mathrm{ml}$ ) alkaline phosphatase $135 \mathrm{IU} / \mathrm{l}) .1,25-$ dihydroxycholecalciferol was not detectable in serum (protein binding assay ${ }^{4}$ ), and this, together with an inappropriately "normal" serum parathormone concentration $\left(0.41 \mu \mathrm{g} / 1, N\right.$ terminal assay $\left.{ }^{2}\right)$ made it unlikely that the hypercalcaemia resulted from sarcoidosis. ${ }^{56}$

Exploration of the right forearm in November 1983 and the right side of the neck in March 1984 failed to locate parathyroid tissue, either at the time of surgery or in the specimens sent for histological examination. Parathyroid hormone concentrations in blood taken from multiple sites in the inferior vena cava and subclavian and innominate veins in May 1984 were all inappropriately high given his hypercalcaemia and did not differ greatly from the value of $0.48 \mu \mathrm{g} / \mathrm{ml}$ in peripheral venous blood $(N$ terminal assay ${ }^{2}$. 


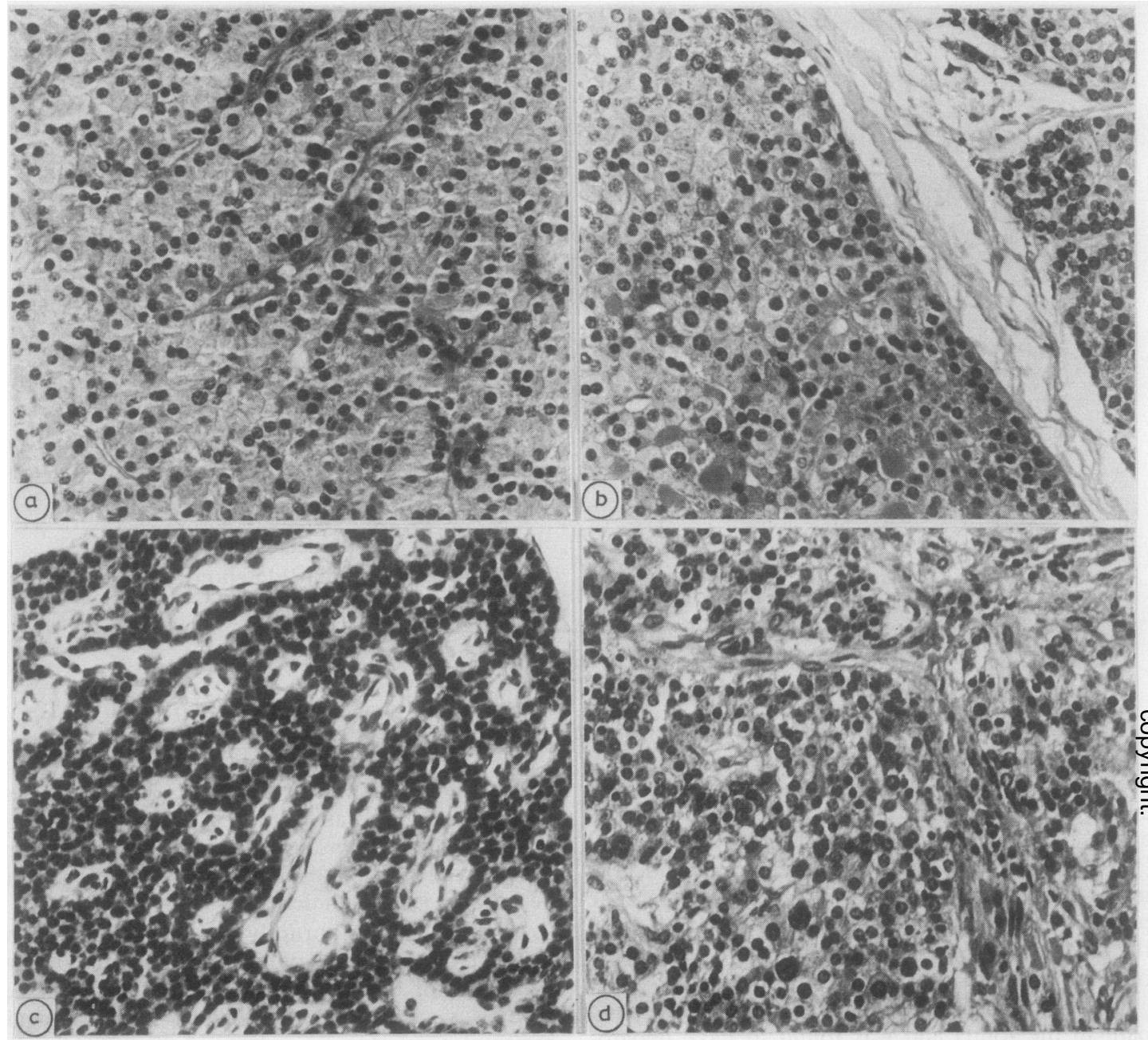

Fig. 3 (a) Left parathyroid removed in 1974. (b) Right inferior parathyroid removed in 1977. (c) Forearm implant (1978). (d) Lung metastasis (1984).

In July 1984 a chest radiograph showed a lesion in the upper lobe of the left lung; its presence was confirmed by computed tomography (Fig. 2). A chest radiograph one year previously had not shown the lesion. The nature of the lesion had still not been elucidated when he was admitted to hospital in October 1984 with grand mal convulsions. He was hypotensive with two separate fractures in the left side of the pelvis. Despite intravenous treatment with antibiotics he died two days after admission.

\section{PATHOLOGICAL FINDINGS}

A tumour $0.5 \mathrm{~cm}$ in diameter was found in the apex of the left lung corresponding to the nodule seen on the radiograph. No other evidence of tumour was found, and examination of the neck and right fore- arm showed no evidence of remaining parathyroid tissue. Bronchopneumonia was present, which was considered to have been the ultimate cause of death.. The hilar lymph glands were large and calcified. The single right kidney weighed $120 \mathrm{~g}$ and had been largely replaced by cystic spaces.

A review of the sections of the laryngectomy specimen of 1974 showed an enlarged parathyroid gland (maximum diameter $1.2 \mathrm{~cm}$ ) in a random $\omega$ block of left lobe of thyroid. This showed nodular chief cell hyperplasia with occasional mitoses (Fig.응 3a). At parathyroidectomy in 1977 both right parathyroid glands were enlarged and nodular. The right:inferior gland weighed $8.1 \mathrm{~g}$ and was encapsulated ${ }_{-}^{-}$ by fibrous tissue. Microscopically, there was coarse ${ }_{\mathbb{N}}$ fibrous trabeculation, the parenchyma being com- $\Omega$ 
posed mainly of chief cells with sparse mitotic activity and moderate nuclear pleomorphism (Fig. 3b). The appearance was considered to be suggestive of but not absolutely diagnostic of parathyroid carcinoma. We thought that the fibrosis, though an accepted feature of malignancy, could have resulted directly from radiotherapy in this case. The right superior gland, part of which had been transplanted to the forearm, weighed $0.4 \mathrm{~g}$. Microscopically, it showed multiple small adenomas and some areas of fibrous scarring. The parathyroid implant removed from the forearm in 1978 (size $2 \times 0.5 \mathrm{~cm}$ ) had a similar appearance to the adenomatous areas of the right superior gland from which it had been taken, with little nuclear pleomorphism and no mitoses (Fig. 3c). The small tumour found at necropsy in the left lung was composed of parathyroid tissue with moderate nuclear pleomorphism but no mitoses and relatively little fibrosis (Fig. 3d). The diagnosis of parathyroid malignancy was based more on the fact that this parathyroid tissue had metastasised rather than on its histological appearances alone. The surrounding lung contained small hyaline fibrotic nodules (burnt out sarcoid) and calcification of the alveolar walls (secondary to hypercalcaemia). The hilar lymph nodes showed hyaline fibrous effacement and patchy calcification compatible with old sarcoidosis. Sections of bone taken from the femur in 1983 and at postmortem examination showed active osteitis fibrosa.

\section{Discussion}

Parathyroid cancer presents typically with hypercalcaemia, ${ }^{78}$ although $10 \%$ or so of malignant tumours are non-functioning. ${ }^{9}$ Our failure to make the diagnosis before the postmortem examination in this patient resulted, in part at least, from the fact that several plausible alternative explanations for his hypercalcaemia existed and may, indeed, have contributed in varying degrees at different times. These included parathyroid hyperplasia and formation of adenoma, sarcoidosis, and laryngeal squamous carcinoma.

Overactivity of the parathyroid gland, with both hyperplasia and formation of adenoma is often present, even in the early stages of chronic renal failure. ${ }^{10}$ Parathyroid carcinoma has been reported in several patients receiving dialysis ${ }^{7-9}$ perhaps as a result of malignant change in initially benign lesions. ${ }^{71112}$ Distinguishing benign parathyroid lesions from parathyroid cancer may, however, be difficult. We based our diagnosis of malignancy in our patient on the criterion of metastatic spread to the lung. It was not possible to know whether spread of malignant parathyroid cells via the blood took place before operation in 1977 or whether the source of these cells was parathyroid tissue implanted into the forearm. Local invasiveness of such implants has been reported ${ }^{13}$ but metastatic spread has not. The histological appearance of the lesion in the lung most closely resembled that of the right inferior parathyroid gland removed in 1977 , and on this basis we think that the lesion most probably came from this source. Features that point to malignancy are mitotic activity, fibrous trabeculation, and vascular or capsular invasion..$^{78912}$ The fibrous nature of the right inferior parathyroid gland removed from the neck in 1977 raised the possibility of the presence of carcinoma, but none of the other criteria for malignancy was satisfied.

Ionising radiation is known to cause malignant tumours of the thyroid ${ }^{14}$ is and has also been shown to produce hyperparathyroidism in man and experimental animals. ${ }^{15}$ Histologically, the affected glands have been parathyroid adenomas with considerable fibrosis, a description that corresponds to that of the sections from the right inferior gland taken in 1977 from our patient. Thus the fibrosis known to occur in malignancy also occurs after irradiation of the parathyroid, and it is difficult to know what emphasis to put on this feature. Radiation may have induced parathyroid cancer in our patient. The latent period for the induction of benign parathyroid lesions in man has been reported as being between five and 61 years after irradiation. ${ }^{17}$ We were able to find only one previous case of parathyroid cancer, diagnosed 53 years after irradiation of the neck. ${ }^{12}$ Our patient received irradiation to a parathyroid already chronically stimulated because of renal failure and so, in theory, already had a raised potential for malignant transformation. Although, for the reasons outlined above, we think it unlikely that the pulmonary metastasis was derived from the forearm, this is a possibility.

Our generally favourable results with subtotal parathyroidectomy and autotransplantation were recently reported. ${ }^{18}$ Despite general approval for total parathyroidectomy and autotransplantation our experience with this patient leads us to believe that it is inadvisable to transplant irradiated parathyroid tissue, and we now regard previous irradiation of the neck as a contraindication to autotransplantation.

We thank Professor G Taylor, who performed most of the surgery, Miss C Judge for secretarial help, and Mr J Hopwood and Mrs K O' Keefe for photography and graphics. Dr S Fleming is in receipt of a grant from the St Bartholomew's Hospital Renal Aid Group. 
References

' Tomlinson S, O' Riordan JLH. The parathyroids. Br J Hosp Med 1978; 19:40-53.

${ }^{2}$ Brodie MJ, Boobis AR, Dollery CT, et al. Rifampicin and vitamin D metabolism. Clin Pharmacol Ther 1980;27:810-4.

${ }^{3}$ O'Riordan JLH, Watson L, Woodhead JS. Secretion of parathyroid hormone in primary hyperparathyroidism. Clin Endocrinol 1972;1:149-55.

4 Mallon JP, Hamilton JG, Nauss-Karol C, et al. An improved competitive protein binding assay for 1,25 dihydroxyvitamin D. Arch Biochem Biophys 1980;201:277-85.

5 Barbour GL, Coburn JW, Slatopolsky E, Norman AW, Horst RL. Hypercalcaemia in an anephric patient with sarcoidosis: evidence for extrarenal generation of 1,25-dihydroxyvitamin D. N Engl J Med 1981;305:440-3.

- Bell NH, Stern PH, Pantzer E, Sinha TK, De Luca HF. Evidence that increased circulating $1 \alpha, 1,25$-dihydroxyvitamin $\mathrm{D}$ is the probable cause for abnormal calcium metabolsim in sarcoidosis. J Clin Invest 1979;64:218-25.

' Anderson BJ, Samaan NA, Vassilopoulou-Sellin R, Ordonez NG, Hickey RC. Parathyroid carcinoma: features and difficulties in diagnosis and management. Surgery 1983;94:906-15.

${ }^{8}$ McKeown PP, McGarity WC, Sewell CW. Carcinoma of the parathyroid gland: is it overdiagnosed? Am J Surg 1984; 147:292-8.

9 Berland Y, Olmer M, Lebreuil G, Grisoli J. Parathyroid carcinoma, adenoma and hyperplasia in a case of chronic renal insufficiency on dialysis. Clin Nephrol 1982; 18:154-8.

${ }^{10}$ Akerstrom G, Malmaeus J, Grimelius L, Ljunghall S, Bergstrom R. Histological changes in parathyroid glands in subclinical and clinical renal disease. Scand J Urol Nephrol 1984; 18:7584.

"Desch CE, Arsensis G, Woolf PD, May AG, Amatruda JM. Parathyroid hyperplasia and carcinoma within one gland. Am J Med 1984;77:131-4.

${ }^{12}$ Smith JF, Coombs RRH. Histological diagnosis of carcinoma of the parathyroid gland. J Clin Pathol 1984;37:1370-8.

${ }^{13}$ Frei U, Klempa I, Schneider M, Scheuermann EH, Koch KM. Tumour-like growth of parathyroid autografts in uraemic patients. Proc Eur Dial Transplant Assoc 1981;18:548-55.

${ }^{14}$ Makarewicz CR. Radiation and thyroid cancer. JAMA 1984;251: 1280 .

is Hedman I, Tisell LE. Associated hyperparathryoidism and non medullary thyroid carcinoma; the aetiologic role of radiation. Surgery 1984;95:392-7.

${ }^{16}$ Wynford-Thomas V, Wynford-Thomas D, Williams ED. Experimental induction of parathyroid adenomas in the rat. Journal of the National Cancer Institute 1982;70:127-31.

${ }^{17}$ Karstrup S, Hegedüs L, Sehested M. Hyperparathryoidism after neck irradiation for Hodgkin's disease. Acta Med Scand 1984;215: 287-8.

${ }^{18}$ Welsh CL, Taylor GW, Cattell WR, Baker LRI. Parathyroid Surgery in chronic renal failure: subtotal parathyroidectomy or autotransplantation? Br J Surg 1984;71:591-2.

Requests for reprints to: Dr JP Ireland, DHSS Department of Toxicology, St Bartholomew's Hospital Medical College, Dominion House, Barts Close, London EC1, England. 